\title{
Analgesic Profile of the Aqueous and Methanol Extracts of Alchornea Laxiflora in Albino Mice
}

\section{Chukwunwike Nwonu}

Division of Neuropharmacology and Behaviour, Department of Pharmacology and Therapeutics, Faculty of Basic and Allied Medical Sciences, College of Health Sciences, Benue State University, Nigeria

\section{Olapade Ilesanmi}

Department of Pharmacology, Faculty of Pharmacy, Obafemi Awolowo University, Ile-Ife, Osun State, Nigeria

\section{Joseph Agbedahunsi}

Drug Research and Production Unit, Faculty of Pharmacy,

Obafemi Awolowo University, Ile-Ife, Osun State, Nigeria

\section{Patience Nwonu}

Department of Pharmacology and Toxicology, Faculty of Pharmaceutical

Sciences, University of Nigeria, Nsukka, Enugu State, Nigeria

Doi: 10.19044/esj.2018.v14n24p134 URL:http://dx.doi.org/10.19044/esj.2018.v14n24p134

\begin{abstract}
The study investigated the median lethal dose and the effects of the aqueous and methanol extracts of Alchornea laxiflora in three mouse models of central and peripheral analgesia, the hot plate, acetic acid-induced abdominal writhes and the tail immersion tests. This was with a view to providing information on the acute toxicity, analgesic effects and the possible mechanism of analgesia. The $\mathrm{LD}_{50}$ for the aqueous and methanol extracts of A. laxiflora in the oral route was $>1600 \mathrm{mg} / \mathrm{kg}$ respectively, and found to be safe in animals. However, the $\mathrm{LD}_{50}$ (i.p.), was found to be $400 \mathrm{mg} / \mathrm{kg}$ for the methanol extract, which was relatively toxic and $>1600 \mathrm{mg} / \mathrm{kg}$ for the aqueous extract. Mice of both sexes $(\mathrm{n}=6)$ weighing $18-22 \mathrm{~g}$ were used for the study, which were randomised into control and test, which summed up to eight (VIII) groups. The control group (I) received $10 \%$ Tween 80 (vehicle), $0.1 \mathrm{ml} / 10 \mathrm{~g}$ mouse while the test groups (II,III,IV,V,VI) were administered graded doses $(100,200,400,800,1600 \mathrm{mg} / \mathrm{kg}$, p.o.) of the extracts. The reference groups (VII,VIII) received standard drugs, Acetyl salicylic acid (10 mg/kg, i.p.) and Pethidine $(10 \mathrm{mg} / \mathrm{kg}$, i.p.). The animals were observed for their reaction to pain using different noxious stimuli (thermal and chemical). They were appropriately scored individually after observation 30 and 60 min post intraperitoneal and oral administrations of vehicle, extracts or drugs respectively.
\end{abstract}


The results showed that $A$. laxiflora produced significant $(\mathrm{P}<0.05)$ increase in the mean reaction time to pain in the hot plate and the tail immersion tests. It also produced a significant $(\mathrm{P}<0.05)$ decrease in the number of abdominal writhes. The study concluded that $A$. laxiflora possesses analgesic activity. The mechanism of the analgesic effect was not through the opioidergic system.

Keywords: Alchornea laxiflora, hot plate, abdominal writhe, tail immersion and mice.

\section{Introduction}

Alchornea laxiflora (Bentham) Pax and Hoffman (Euphorbiaceae) is a deciduous shrub or a forest understorey tree (found between the forest canopy and the ground cover) of about $6 \mathrm{~m}$ high growing in Nigeria. The leaves are thinly textured turning an attractive yellow or red in dry season, while the young leaves appear purple in colour (Hutchinson and Dalziel, 1937). It is found in the river-rine vegetation and mixed deciduous woodland, often on rocky outcrops in the Cameroons, and it is widespread in the Central and Southern tropical Africa. A. laxiflora is commonly known as lowveld beadstring, while the local names are Urievwu (Urhobo), Uwenuwen (Edo), Ububo (Igbo), Ijan or Pepe (Yoruba).

The leaves of $A$. laxiflora are employed in ethnomedicine for the management of neurological and cardiovascular disorders viz. anxiety, insomnia, hypertension etc. The decoction of the leaves is used in the treatment of inflammatory and infectious diseases, as well as an important component of anti-malarial formulations (Adewole, 1993). The leaves are recorded as amongst those used to preserve the moisture of kolanuts in packing (Muanya, 2009). The stem (especially, the branchlets) is used in Nigeria as chewing sticks for teeth cleaning (Farnsworth et al., 1985). The plant enters the Yoruba incantation to make "bad medicine" rebound to sender (Burkill, 1994). A previous report has demonstrated that extract from the leaves of $A$. laxiflora can reverse sickling phenomenon in vitro, and thus can be employed in the management of Sickle cell anaemia (Muanya, 2009). The bioactive chemical constituents from A. laxiflora include flavonoid, which was the preponderant constituent in the leaves of the plant but present in lesser quantities in the roots and stems, and exhibit anti-microbial activity (Ogundipe et al., 2001), and this activity has been found to be significant against gram ve and gram +ve organisms. This justifies the use of the plant as chewing stick in folkloric medicine. Farombi et al. (2003) demonstrated the anti-oxidant property of $A$. laxiflora leaf and root extracts, thus validating its use in the preservation of the moisture content of kolanuts during packing. A more recent study has also, shown that the methanolic leaf extract of A. laxiflora demonstrated sedative and anxiolytic activities in mice in vivo (Nwonu, 2011). 
This novel development coupled with the fact that no known pharmacological studies on the central nervous system effects of $A$. laxiflora has been done, necessitated further scientific enquiry into the analgesic properties and mechanism of the plant.

\section{Materials and Methods \\ Plant Collection}

Alchornea laxiflora Bentham leaves were collected in the month of February, 2013 at the medicinal plant garden, Pharmacognosy plot II, Teaching and Research Farm located within the Obafemi Awolowo University campus. The plant was identified and authenticated in the Faculty of Pharmacy herbarium by Mr. Ifeoluwa I. Ogunlowo, a taxonomist with the Department of Pharmacognosy. A voucher specimen (Voucher number: Ife 17592) of the leaves of $A$. laxiflora was deposited at the Department of Botany, Obafemi Awolowo University, Ile-Ife, Nigeria.

\section{Plant Extraction}

The leaves of the plant were allowed to air-dry at laboratory room temperature (about $37{ }^{\circ} \mathrm{C}$ ), and then pulverised, using a milling machine (Christy and Dorris Ltd., Model No. 7445). The powdered plant material (350 g) was subjected to cold extraction in a percolator (thrice) using 2.5 litres of $100 \%$ methanol (absolute methanol) for 72 hours, with occasional stirring. The marc was re-extracted using another equal volume of methanol for 72 hours. The filtrate generated was concentrated to dry residue in a rotary evaporator under reduced pressure at $40{ }^{\circ} \mathrm{C}$. The extraction process yielded $90.0 \mathrm{~g}$ of sticky, black crude extract $(25.7 \%)$. The aqueous extraction process was carried out using hot extraction method. The pulverised plant (500 g) was extracted using boiling method under reflux. The extraction was made to simmer for 3 hours. The decoction (menstrum) was concentrated to dryness in vacuo using the rotary evaporator at $40^{\circ} \mathrm{C}$. Little amount of methanol was added to the aqueous extract to facilitate easy concentration to dryness. The weight of the dry extracts was determined and the percentage yield calculated. The extraction process for the decoction yielded $38.6 \mathrm{~g}(7.7 \%)$ of a sticky, dark brown crude extract.

\section{Animals}

Adult albino mice (Vom strain of the National Veterinary Research Institute, Vom, Jos, Nigeria) of both sexes $(18-22 \mathrm{~g})$ were used in the study. Animals were bred and housed in galvanised cages in a well-lit and aerated room of 12/12 h light/dark cycle in the animal facility, Faculty of Pharmacy, Obafemi Awolowo University, Ile-Ife. Animals had unimpeded access to safe drinkable water and standard laboratory pellet diet (Guinea Feeds Brand, 
Bendel Feeds and Flour Mills, Ltd, Ewu, Edo State, Nigeria). The animal cages were regularly cleaned. All the animals were maintained on ideal environmental and nutritional state throughout the period of the study. Animals were allowed to acclimatize for $30 \mathrm{~min}$ before being used for experiment where they were moved from the animal facility to the laboratory. The guidelines for the care and use of animals in neuroscience and behavioural research (NIH, 1991 and NRC, 1996) were strictly adhered to.

\section{Preparation and Dosing}

A. laxiflora extracts were prepared fresh on each day of the experiment using $10 \%$ Tween 80 as vehicle. All the extracts were administered to animals. The volume of the vehicle used was $0.1 \mathrm{ml} / 10 \mathrm{~g}$ mouse. Injection was administered slowly orally for the test doses, while both the oral and intraperitoneal routes were used in the determination of acute toxicity and the $\mathrm{LD}_{50}$

\section{Drugs}

The following drugs and chemical reagents were used in the study: Acetyl salicylic acid and ethanol (BDH Chemicals Ltd., Poole, England), Naloxone, Pethidine and Polyoxyethylene sorbitan monotolate (Tween 80) (SigmaAldrich Inc., St. Louis, USA) and Glacial acetic acid (May and Baker, England).

\section{Experimental Designs Acute Toxicity Tests}

The acute toxicity and $\mathrm{LD}_{50}$ of the plant extracts were determined using the Lorke's Method (1983) with minor modifications. The graded doses (200, $400,800,1600,3200 \mathrm{mg} / \mathrm{kg}$, i.p. and p.o.) of A. laxiflora (ALM) were used for toxicity test. The number of death(s), behavioural changes including, the nature of death and time of death were recorded. One animal $(n=1)$ was used for each dose level in phase I study, while four animals $(n=4)$ of three dose levels were chosen in the phase II. The same procedure was employed in both the intra-peritoneal and the oral routes of toxicity test. $\mathrm{LD}_{50}$ (the index of acute toxicity) was calculated within $24 \mathrm{~h}$. Animals were observed hourly for the first $8 \mathrm{~h}$, then 6 hourly for $24 \mathrm{~h}$, and then daily for 14 days (Wafai and Mehta, 1986). The number of deaths were recorded on the day of experiment, and those that survived the acute toxicity were weighed daily for 14 days. Increase in the weights of the animals were regarded as having survived the acute toxicity, and thus ended the experiment. 


\section{Assessment of the Analgesic Activity of A. laxiflora in Mice Hot Plate Test}

The analgesic activity of ALM was assessed using the digital hot plate analgesia meter Columbus Ohio (Model No. 43204, USA). The method described by Gupta et al. (1999) was adopted in the study. The reaction time (paw licking or jumping) was recorded at 0, 30, 60, 90 and $120 \mathrm{~min}$ post administration of control (10\% Tween $80,0.1 \mathrm{ml} / 10 \mathrm{~g}$ mouse, p.o.) or ALM $(100,200,400,800$ and $1600 \mathrm{mg} / \mathrm{kg}$, p.o.). The temperature of the plate was maintained at $55 \pm 0.5^{\circ} \mathrm{C}$. A cut off reaction time of $15 \mathrm{sec}$ was chosen in order to avoid injury to the test animals (Kuraishi et al., 1983). Acetylsalicylic acid (ASA) $(10 \mathrm{mg} / \mathrm{kg}$, i.p.) and Pethidine $(10 \mathrm{mg} / \mathrm{kg}$, i.p. $)$ both served as reference (standard) drugs.

\section{Acetic Acid-Induced Abdominal Writhes Test}

The method of Koster et al. (1959) was adopted. Groups of mice $(n=5)$ were used for controls and test experiments. One hour after the administration of graded doses of ALM (100, 200, 400, 800 and $1600 \mathrm{mg} / \mathrm{kg}$, p.o.), the mice were administered $0.7 \% \mathrm{v} / \mathrm{v}$ of glacial acetic acid (volume of injection 0.1 $\mathrm{ml} / 10 \mathrm{~g}$ mouse) intraperitoneally. The mice were placed individually into the observation cage, and $5 \mathrm{~min}$ post administration, the number of writhes produced in these animals were counted for $10 \mathrm{~min}$. A writhe refers to the stretching of the abdomen with simultaneous stretching of at least one hind limb (Hosseinzadeh and Younesi, 2002). Control group received $10 \%$ Tween 80 (0.1 ml/10 g, p.o.), while ASA (10 mg/kg, i.p.) and Pethidine (10 mg/kg, i.p.) were used as reference drugs. Naloxone $(2 \mathrm{mg} / \mathrm{kg}$, s.c.) was administered $15 \mathrm{~min}$ prior to ALM (1600 mg/kg, p.o.) or Pethidine $(10 \mathrm{mg} / \mathrm{kg}$, i.p.) in another study involving six (6) different groups of animals $(n=5)$.

\section{Tail Immersion Test}

The method previously described by Janssen et al. (1963) was adopted. A permanent marker was used to delineate the lower $5 \mathrm{~cm}$ of the animal's tail prior to its immersion into a plastic container with water heated to a temperature of $55 \pm 0.5{ }^{\circ} \mathrm{C}$. The response latency between the onset of immersion and the withdrawal of the animal's tail from the hot water container was recorded, with a cut-off tail withdrawal time of $10 \mathrm{~s}$. This ensured that experimental animals were not thermally injured. Baseline reading was taken $1 \mathrm{~h}$ pre- and post administration of graded doses (100, 200, 400, 8001600 $\mathrm{mg} / \mathrm{kg}$, i.p.) of ALM, and $30 \mathrm{~min}$ before and after injection of reference drugs (ASA $10 \mathrm{mg} / \mathrm{kg}$, i.p. and Pethidine $10 \mathrm{mg} / \mathrm{kg}$, i.p.). 


\section{Statistical Analysis}

Results were expressed as Mean \pm S.E.M. Analysis of data was done using one-way ANOVA and multiple comparison of treatment groups performed by employing the Student-Newman-Keuls test using the primer of biostatistics (Version 3.01) (Glantz, 1992). Probability level of $\mathrm{P} \leq 0.05$ (5\%) was considered statistically significant for all treatments relative to control (Steel and Torrie, 1960).

\section{Results}

The $\mathrm{LD}_{50}$ was $400 \mathrm{mg} / \mathrm{kg}$, i.p. and $>1600 \mathrm{mg} / \mathrm{kg}$, p.o. for the methanol extract, and $>1600 \mathrm{mg} / \mathrm{kg}$, i.p. and p.o. for the aqueous extract.

Table 1. Hot Plate Test: Effect of the Methanol Extract of A. laxiflora on Pain

\begin{tabular}{lccccc}
$\begin{array}{c}\text { Treatment group } \\
\text { (mg/kg. p.o.) }\end{array}$ & 0 & 30 & 60 & 90 & 120 \\
\hline CTR & $4.02 \pm 0.54$ & $5.54 \pm 0.79$ & $5.14 \pm 0.79$ & $6.44 \pm 0.55$ & $6.40 \pm 0.71$ \\
100 & $6.46 \pm 0.73$ & $10.04 \pm 1.87$ & $11.04 \pm 0.85^{*}$ & $10.44 \pm 1.17$ & $12.18 \pm 1.24$ \\
200 & $5.34 \pm 0.43$ & $9.72 \pm 1.67$ & $11.24 \pm 1.60^{*}$ & $9.68 \pm 0.89$ & $10.62 \pm 1.44$ \\
400 & $6.72 \pm 0.73$ & $7.48 \pm 1.86$ & $8.10 \pm 1.67$ & $7.34 \pm 1.53$ & $7.52 \pm 1.07$ \\
800 & $7.34 \pm 0.66^{*}$ & $11.72 \pm 1.67$ & $10.14 \pm 1.27$ & $9.48 \pm 1.88$ & $8.56 \pm 1.00$ \\
1600 & $5.38 \pm 0.94$ & $7.82 \pm 2.04$ & $8.84 \pm 1.74$ & $11.56 \pm 1.95$ & $11.70 \pm 1.01$ \\
ASA (10 mg/kg, i.p.) & $7.76 \pm 0.91^{*}$ & $9.96 \pm 2.10$ & $6.76 \pm 0.7$ & $10.34 \pm 1.29$ & $11.26 \pm 1.73$ \\
PTD (10 mg/kg, i.p.) & $7.58 \pm 0.98^{*}$ & $9.16 \pm 1.22$ & $10.24 \pm 1.62^{*}$ & $11.66 \pm 2.01$ & $12.40 \pm 1.60$ \\
\hline
\end{tabular}

One-way ANOVA revealed a significant $(\mathrm{F}=2.95 ; \mathrm{P}=0.017)$ difference between the treatment groups in the baseline $(0 \mathrm{~min})$ at $800 \mathrm{mg} / \mathrm{kg}$, p.o. and the reference drugs, and at 60 min after administration of ALM: $\mathrm{F}=2.81 ; \mathrm{P}=$ 0.018 at $100 \mathrm{mg} / \mathrm{kg}$, p.o. and $200 \mathrm{mg} / \mathrm{kg}$, p.o. and PTD (10 mg/kg, p.o.), a reference drug. *Indicates a significant difference from control, $10 \%$ Tween 80 .

Table 2. Hot Plate Test: Effect of the Aqueous Extract of A. laxiflora on Pain Treatment group Mean Reaction Time To Pain (Min)

\begin{tabular}{lccccc} 
(mg/kg, p.o.) & 0 & 30 & 60 & 90 & 120 \\
\hline CTR & $4.02 \pm 0.54$ & $5.54 \pm 0.79$ & $5.14 \pm 0.79$ & $6.44 \pm 0.55$ & $6.40 \pm 0.71$ \\
100 & $6.06 \pm 0.56$ & $8.30 \pm 1.72$ & $9.14 \pm 1.52$ & $8.66 \pm 1.50$ & $9.38 \pm 1.67$ \\
200 & $5.90 \pm 0.29$ & $5.44 \pm 0.92$ & $8.06 \pm 1.40$ & $6.68 \pm 0.43$ & $10.92 \pm 1.80$ \\
400 & $4.76 \pm 0.65$ & $8.22 \pm 1.09$ & $10.60 \pm 1.34$ & $8.50 \pm 0.77$ & $12.62 \pm 1.12$ \\
800 & $8.50 \pm 0.53 *$ & $12.18 \pm 1.41 *$ & $11.78 \pm 1.33^{*}$ & $10.76 \pm 1.65$ & $12.18 \pm 1.49$ \\
1600 & $5.84 \pm 0.81$ & $11.64 \pm 1.47 *$ & $11.22 \pm 1.35^{*}$ & $11.18 \pm 1.72$ & $8.86 \pm 0.79$ \\
ASA (10 mg/kg, i.p.) & $7.76 \pm 0.91 *$ & $9.96 \pm 2.10$ & $6.76 \pm 0.74$ & $10.34 \pm 1.29$ & $11.26 \pm 1.73$ \\
PTD (10 mgkg, i.p.) & $7.58 \pm 0.98 *$ & $9.16 \pm 1.22$ & $10.24 \pm 1.62 *$ & $11.66 \pm 2.01$ & $12.40 \pm 1.60$ \\
\hline
\end{tabular}


One-way ANOVA revealed a significant difference between the treatments at baseline $(0 \mathrm{~min}): \mathrm{F}=4.95 ; \mathrm{P}=0.000,30 \mathrm{~min}: \mathrm{F}=3.20 ; \mathrm{P}=0.011$ and at 60 min: $\mathrm{F}=3.18 ; \mathrm{P}=0.011 ; 800 \mathrm{mg} / \mathrm{kg}$, p.o., 800 and $1600 \mathrm{mg} / \mathrm{kg}$, p.o. and, 800 and $1600 \mathrm{mg} / \mathrm{kg}$, p.o. respectively. *Indicates a significant difference from control, $10 \%$ Tween 80 .

Table 3. Tail Immersion Test: Effect of the Methanol Extract of A. laxiflora on Pain

\begin{tabular}{lll}
\hline $\begin{array}{c}\text { Treatment group } \\
(\mathrm{mg} / \mathrm{kg}, \text { p.o. })\end{array}$ & Baseline (0 Min) & $\begin{array}{l}\text { Post Baseline } \\
\text { Min })\end{array}$ \\
\hline CTR & $1.34 \pm 0.33$ & $1.44 \pm 0.38$ \\
100 & $2.38 \pm 0.29$ & $3.04 \pm 0.24^{*}$ \\
200 & $1.44 \pm 0.24$ & $3.18 \pm 0.35^{*}$ \\
400 & $2.36 \pm 0.43$ & $2.58 \pm 0.42$ \\
800 & $2.40 \pm 0.24$ & $2.58 \pm 0.42$ \\
1600 & $2.60 \pm 0.22$ & $2.98 \pm 0.26^{*}$ \\
ASA $(10 \mathrm{mg} / \mathrm{kg}$, i.p. $)$ & $1.56 \pm 0.26$ & $2.26 \pm 0.23$ \\
PTD $(10 \mathrm{mg} / \mathrm{kg}$, i.p. $)$ & $1.62 \pm 0.32$ & $3.18 \pm 0.54^{*}$ \\
\hline
\end{tabular}

One-way ANOVA revealed no significant difference between the treatments: $\mathrm{F}=2.86 ; \mathrm{P}=0.019$ at baseline $(0 \mathrm{~min})$. However, after $60 \mathrm{~min}$ of extract administration, a significant $(\mathrm{F}=2.57 ; \mathrm{P}=0.032)$ difference was observed at 100,200 and $1600 \mathrm{mg} / \mathrm{kg} /$ p.o. *Indicates a significant difference from control, $10 \%$ Tween 80 .

Table 4. Tail Immersion test: Effect of the Aqueous Extract of A. laxiflora on Pain

\begin{tabular}{lll}
\hline $\begin{array}{c}\text { Treatment group } \\
(\mathrm{mg} / \mathrm{kg}, \text { p.o. })\end{array}$ & Baseline (0 Min) & Post Baseline (60 Min) \\
\hline CTR & $1.34 \pm 0.33$ & $1.44 \pm 0.38$ \\
100 & $2.22 \pm 0.39$ & $2.36 \pm 0.12$ \\
200 & $1.98 \pm 0.30$ & $2.08 \pm 0.33$ \\
400 & $0.92 \pm 0.15$ & $1.78 \pm 0.27$ \\
800 & $1.14 \pm 0.17$ & $1.18 \pm 0.10$ \\
1600 & $1.58 \pm 0.37$ & $1.62 \pm 0.30$ \\
ASA (10 mg/kg, i.p.) & $1.56 \pm 0.26$ & $2.26 \pm 0.23$ \\
PTD (10 mg/kg, i.p.) & $1.62 \pm 0.32$ & $3.18 \pm 0.54^{*}$ \\
\hline
\end{tabular}

One-way ANOVA revealed no significant difference between the treatments: $\mathrm{F}=1.92 ; \mathrm{P}=0.099$ at baseline $(0 \mathrm{~min})$ and at after $60 \mathrm{~min}$ respectively. However, $60 \mathrm{~min}$ post administration of pethidine was observed to be significant, $\mathrm{F}=4.04 ; \mathrm{P}=0.003$. *Indicates a significant difference from control, $10 \%$ Tween 80 . 


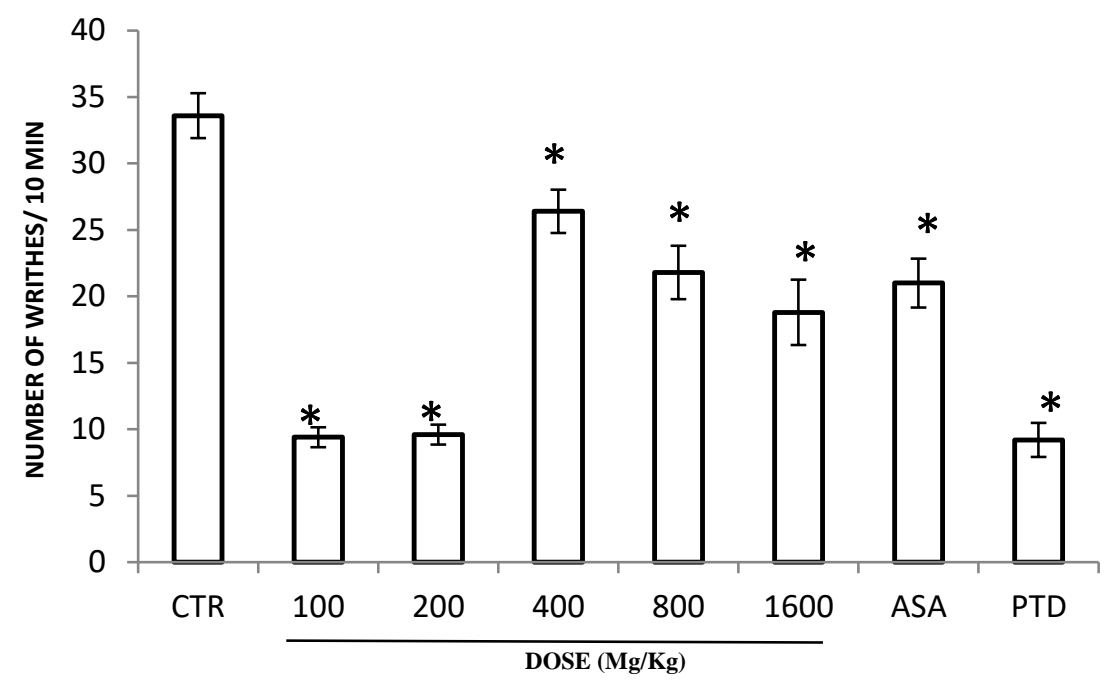

Figure 1. Effect of the Methanol Extract of A. laxiflora on Acetic Acid-induced Writhes

Each bar is expressed as Mean \pm SEM. One-way ANOVA revealed a significant $(\mathrm{F}=29.20 ; \mathrm{P}=0.000)$ difference between the treatment groups. The result shows a significant and dose dependent decrease in the number of abdominal writhes $(400-1600 \mathrm{mg} / \mathrm{kg}$, p.o). The effect of the extract at 100 and $200 \mathrm{mg} / \mathrm{kg}$, p.o. was the highest and comparable to pethidine, the reference drugs.*Indicates a significant difference from control, $10 \%$ Tween 80 .

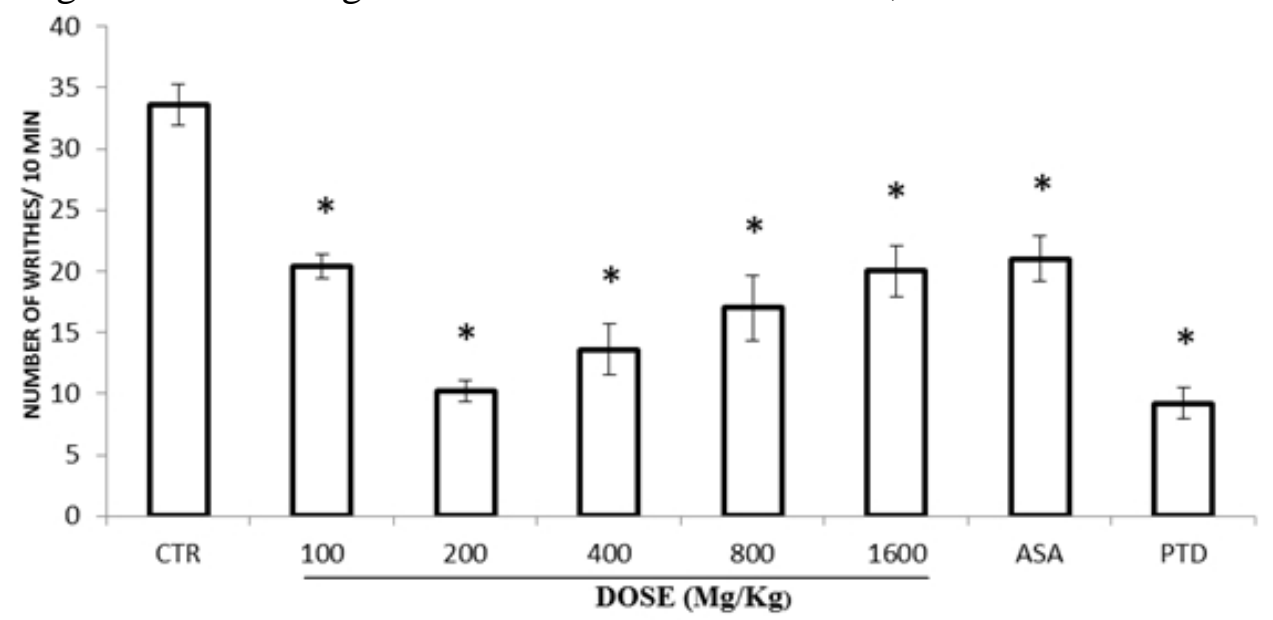

Figure 2: Effect of the Aqueous Extract of A. laxiflora on Acetic Acid-induced Writhes

Each bar is expressed as Mean \pm SEM. One-way ANOVA revealed a significant $(\mathrm{F}=19.01 ; \mathrm{P}=0.000)$ difference between the treatment groups. The result shows a significant decrease in the number of abdominal writhes at $100-1600 \mathrm{mg} / \mathrm{kg}$, p.o. and increase in the number of writhes from $200-1600$ 
$\mathrm{mg} / \mathrm{kg}$, p.o. compared to control. *Indicates a significant difference from control, $10 \%$ Tween 80 .

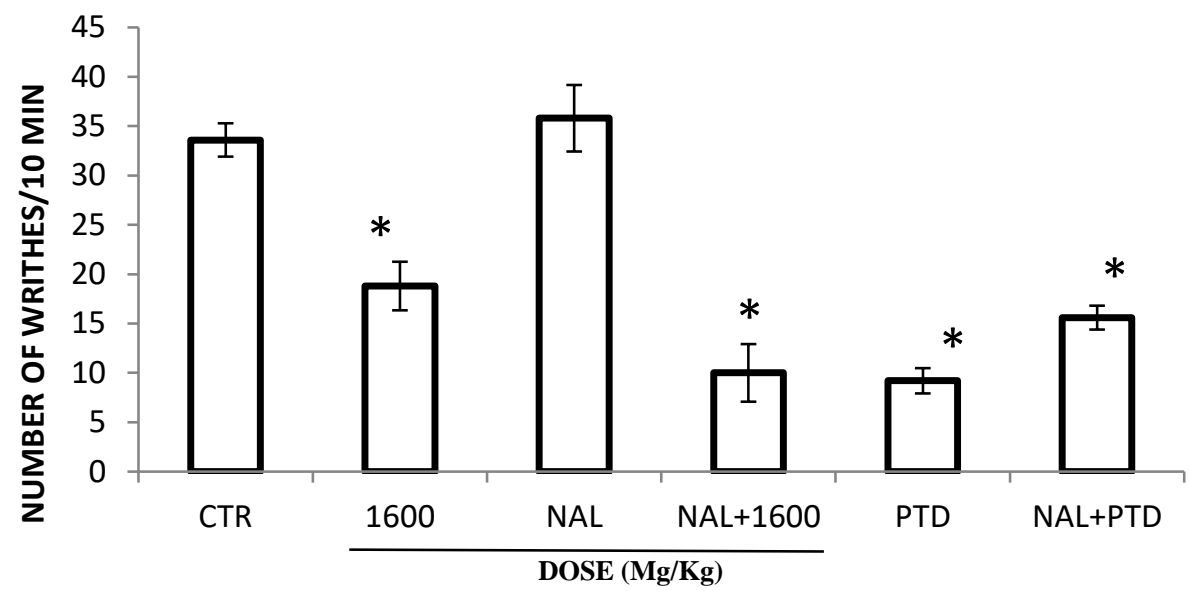

Figure 3: Mechanism of Analgesia in the Methanol Extract of the Leaves of A. laxiflora

Each bar is expressed as Mean \pm SEM. One-way ANOVA revealed a significant $(\mathrm{F}=25.23 ; \mathrm{P}=0.000)$ difference between the treatment groups. The result shows a significant facilitation in the decrease in the number of abdominal writhes by the extract and also, when naloxone was administered prior to the extract. Naloxone significantly blocked the effects of pethidine. *Indicates a significant difference from control, $10 \%$ Tween 80.

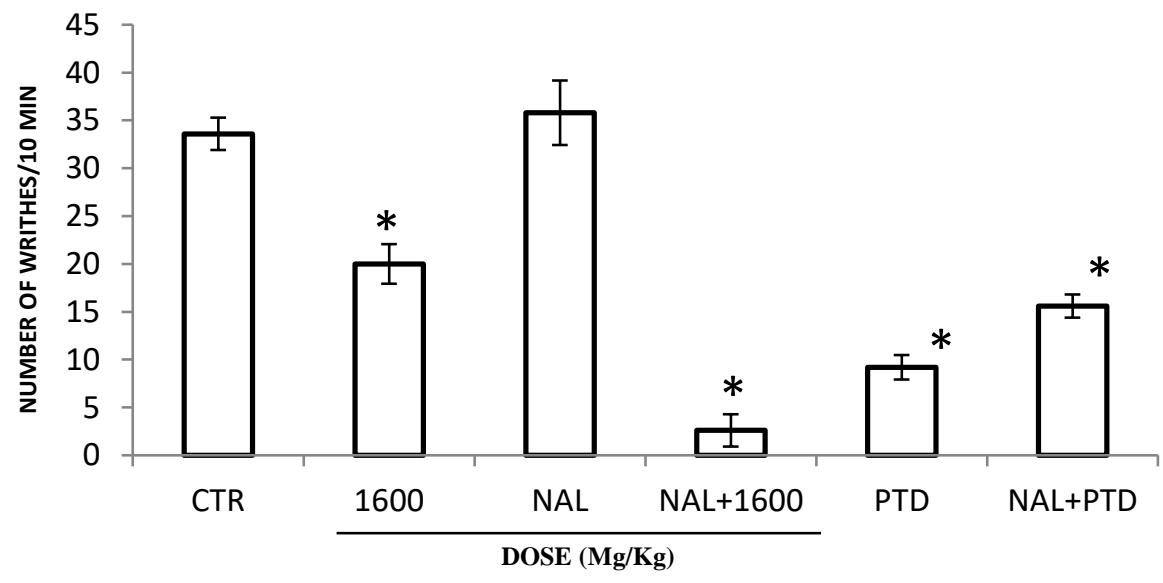

Figure 4: Mechanism of Analgesia in the Aqueous Extract of the Leaves of A. Laxiflora

Each bar is expressed as Mean \pm SEM. One-way ANOVA revealed a significant $(\mathrm{F}=42.77 ; \mathrm{P}=0.000)$ difference between the treatment groups. The result shows a significant facilitation in the decrease in the number of abdominal writhes by the extract, and when naloxone was administered prior 
to the extract. Naloxone significantly blocked the effects of pethidine. *Indicates a significant difference from control, $10 \%$ Tween 80 .

\section{Discussion}

Analgesia refers to conscious neurological or pharmacological state in which the body becomes insensitive to noxious or painful stimuli. It, therefore, means that in a state of analgesia, there is no loss of consciousness and every unpleasant feeling (emotional and sensory) is abolished. Pain is mediated by afferent nerve fibres, i.e., nerve fibres conveying painful or noxious impulses to the CNS where conscious appreciation of pain can be modulated by an array of factors. Analgesia can be induced by diseases of the spinal cord (e.g. Tabes dorsalis, syringomyelia, tumours etc.) and drugs (NSAIDs and opioids). These conditions evoke analgesia by interrupting the neurological (pain) pathway between the sense organs and the CNS (brain and spinal cord). Aside the above, analgesia can be congenital due to a gene mutation. Individuals born with this rare condition do not experience pain when they sustain injuries, and this can be potentially perilous. The central analgesic effects of A. laxiflora were investigated in the hot plate and tail immersion tests, while the acetic acid-induced abdominal writhe model was used to evaluate the peripheral analgesic effect of the methanol and the aqueous extracts of $A$. laxiflora. The different nociceptive paradigms produced different grades of noxious stimuli. Hot plate and tail immersion models are of thermal stimuli, and an increase in the mean reaction time is generally considered to be an important parameter for the assessment of central analgesic activity (Rujjanawate et al., 2003).

In the hot plate test, latency to mean reaction time to pain at all the dose levels tested was sustained incrementally, both horizontally (at the different time intervals) and vertically (in the graded doses of the methanol extract). This was significant at $60 \mathrm{~min}$ interval at low doses. The lowest antinociceptive activity of the methanol extract was observed at a moderately low dose. No significant increase in the mean reaction time to pain was observed at 30, 90 and $120 \mathrm{~min}$ in the tested doses. The analgesic activity of the methanol extract at the different time intervals was comparable to those of the reference drugs, acetyl salicylic acid and pethidine at low and high doses. The mean reaction time to pain in the aqueous extract also, increased horizontally (at the different time intervals) and vertically (in the graded doses of the aqueous extract), which was significant at high doses at 30 and 60 min time intervals. Between 90 and 120 min time intervals in all the tested doses, there was no significant increase in the mean reaction time to pain in the aqueous extract. The central analgesic activity of the methanol and aqueous extracts of A. laxiflora at high doses tested was comparable to that of the reference drug, pethidine (a synthetic opioid receptor agonist), and even surpassed that of acetyl salicylic acid (an NSAID), which is another reference drug. 
The brain and the spinal cord play a pivotal role in central pain mechanism. The dorsal part of the spinal cord is laden with substance P, endogenous opioids, somatostatin, and other inhibitory hormones, which are the targets of pain and inflammation (McCurdy and Scully, 2005). Tail immersion model of pain is a well established and validated protocol for evaluating central analgesic pain through the opioid receptor (McCurdy and Scully, 2005). Opioid analgesics are active against both central and peripheral pain, while the NSAIDs inhibit peripheral pain (Elisabetsky et al., 1995).

The tail immersion test demonstrated central analgesic activity due to prolongation of the mean reaction time to thermal stimuli compared to the baseline latency to the mean reaction time and to that of the control. The prolongation of the mean reaction time to pain in the methanol extract was at all the doses tested, but significant both at low doses and at the highest tested dose in this study. The effect of the methanol extract was higher than that of the reference drug, ASA at all the tested doses, but comparable to that of pethidine at low doses and at the highest tested dose. In the aqueous extract, there was a prolongation in the mean reaction time to pain post baseline (at 60 min). Based on this study, the antinociceptive activity of the methanol extract was comparable to that of the opioids, while that of the aqueous extract can be comparable to the NSAIDs. This demonstrates that the methanol extract had more analgesic activity.

Acetic acid-induced abdominal writhes is a chemical stimulus, and induces tissue damage in the viscera (Ramesh, 2010). The intraperitoneal administration of acetic acid in rodents causes the release of arachidonic acid, which results in the biosynthesis of prostanoids (PGs and Thromboxanes) by COX enzymes (Farias, 2011).

Special nerve endings that sense pain are very sensitive to the PGs. Nerve endings respond to the released $P G$ s via $P G$ receptor which receives and transmits painful impulses to the brain, to produce abdominal visceral writhes (da Silva et al., 2011). It has been suggested that the inhibition of PG synthesis is remarkably efficient as an antinociceptive mechanism in visceral pain (Franzotti, 2002).

The peripheral analgesic effect of $A$. laxiflora exhibited significant percentage inhibition in the abdominal writhes at all the doses tested relative to control, and this effect was comparable to that of the opioids at low doses of the methanol extract, but comparable to the NSAIDs in moderate to high doses. The aqueous extract produced a significant decrease in the number of writhes at all the test doses. A dramatic increase in the number of abdominal writhes occurred immediately after the lowest decrease in the number of abdominal writhes at low dose in the methanol extract, indicating a progressive loss of analgesia with increasing doses of the extract. The percentage inhibition of writhes in the aqueous extract was comparable to the 
opioids at the lowest effective dose while in higher doses, the analgesic activity was comparable to the NSAIDs. The peripheral analgesic effect of $A$. laxiflora may be due to; its action on abdominal visceroceptors (visceral receptors) that are sensitive to glacial acetic acid; to the inhibition of algogenic (causing pain) substances; or the inhibition of transmission of nociceptive impulses through the pain pathway in the central nervous system.

The mechanism of the analgesia by A. laxiflora was investigated in mice to unmask the possible neurological pathway that was involved in mediating the analgesia in the plant extract. Naloxone, a non-selective competitive opioid receptor antagonist was used in the study. Glacial acetic acid was employed to provide the nociceptive stimulus in the animals by generating the abdominal writhes. In the study, naloxone significantly facilitated the decrease in the number of abdominal writhes, thus suggesting that the extracts reduction in the number of writhes were not probably mediated through the opioid receptors. Naloxone, however, significantly blocked the effects of pethidine (meperidine) by stimulating the opioid receptors and increasing the number of writhes in comparison to pethidine administration to the animals alone. This demonstrated the involvement of the opioid pathways in the decrease in the number of writhes by pethidine, a synthetic opioid receptor agonist. The study sufficiently demonstrated the analgesic potency and superiority of the opioids over NSAIDs in all the three mouse models of analgesia used in the study.

\section{Conclusion}

The study concluded that Alchornea laxiflora possesses analgesic activity, producing significant increase in the mean reaction time to pain in the hot plate and the tail immersion tests, and a significant decrease in the number of abdominal writhes. The mechanism of the analgesic effect was not via the opioidergic system.

\section{Acknowledgements}

The authors are grateful to the Government of Nigeria through the Tertiary Education Trust Fund (Presidential Award, TETFund 2012) for providing grant to prosecute the research.

\section{References:}

1. Adewole, A.A. (1993): Personal communication with local traditional medical practitioners in Ibadan, Nigeria.

2. Burkill, H.M. (1994): The useful plants of West Tropical Africa, Edition 2, Vol. 2, Families E-I, Royal Botanic Gardens, Kew: Pp. 144 -150 . 
3. da Silva, J.B., Temponi, V.S., Fernandes, F.V., Alves, G.A.D., Matos, D.M., Gasparetto, C.M., Ribeiro, A., de Pinho, J.J.R.G., Alves, M.S. and de Sousa, O.V. (2011): New approaches to clarify antinociceptive and antinflammatory effects of the extract from Vernonia condesata leaves. International Journal of Molecular Science 12: 8993 - 9008.

4. Elisabetsky, E., Arnador, T.A., Albuquerque, R.R., Nunes, D.S. and Cavalho, A. Do CT. (1995): Analgesic activity of Psychotria colorata (Wild. ex R. and S.) Muell. Arg alkaloids. Journal of Ethnopharmacology 48 (2): $77-88$.

5. Farias, J.A., Ferro, J.N., Silva, J.P., Agra, I.K., Oliveira, F.M., Candea, A.L., Conte, F.P., $\quad$ Ferraris, F.K., Henriques, M.D. and Conserva, L.M. (2011): Modulation of inflammatory processes by leaves extract from Clusia nemorosa both in vitro and in vivo animal models. Inflammation, doi: 10.1007/s10753-011-9372-y.

6. Farnsworth, N.R., Akerele, O., Bingel, A.S., Soejarto, D.D. and Guo, Z.G. (1985): Medicinal plants in therapy, Bull. WHO 63: 965 - 981.

7. Farombi, E.O., Ogundipe, O. O. Uhunwangho, E., Adeyanju, M.A. and Olarenwaju, M.O. (2003): Anti-oxidant properties of extracts from Alchornea laxiflora (Benth.) Pax and Hoffman. Phytotherapy Research 17 (7): $713-716$.

8. Franzotti, E.M., Santos, C.V., Rodrigues, H.M., Mourao, R.H., Andrade, M.R.and Antoniolli, A.R. (2002): Anti-inflammatory, analgesic and acute toxicity of Sida cadifolia Linn. Journal of Ethnopharmacology 72: 273 - 278.

9. Gupta, M., Mazumder, U.K. and Chakrabatis, S. (1999): CNS activities of the methanolic extract of Morringa oleifera root in mice. Fitoterapia 70: $244-250$.

10. Glantz, A.S. (1992): The Primer of Biostatistics (Version 3.01), McGraw-Hills Incorporated.

11. Hosseinzadeh, H. and Younesi, H.M. (2002): Antinociceptive and anti-inflammatory effects of Crocus sativus L. stigma and petal extracts in mice. BMC Pharmacology 2 (7): $1471-2210$.

12. Janseen, P.A., Niemegeers, C.J. and Dony, J. G. (1963): The inhibitory effect of fentanyl and other morphine-like analgesics on the warm water-induced tail withdraw reflex in rats. Arzneimittelforschung 13: $502-507$.

13. Koster, R., Anderson, M. and de Beer, E.J. (1959): Acetic acid for analgesic screening. Federal Proceedings 18: 412.

14. Kuraishi, Y., Harada, Y. and Aratani, S. (1983): Separate involvement of the spinal noradrenergic and serotonergic systems in morphine analgesia: the differences in mechanical and thermal analgesic tests. Brain Research 273 (2): 245 - 252. 
15. McCurdy, C.R. and Scully, S.S. (2005): Analgesic substances derived from natural products (natureceuticals). Life Sciences 78 (5): $476-$ 484.

16. Lorke, D. (1983): A new approach to practical acute toxicity testing. Archives of Toxicology 54: $275-287$.

17. Hutchinson, J. and Dalziel, J.M. (1937): Flora of West Tropical Africa. Crown Agents for Overseas Government and Administration, London, Vol. 1 (2): $600-605$.

18. Muanya, C. (2009): Herbal medication shows promise in the management of Sickle cell anaemia. The Guardian, February 19, Pp. $35-36$.

19. NIH (1991): Guidelines for the care and use of animals in neuroscience and behavioural research.National Institutes of Health.

20. NRC (1996): Guidelines for the care and use of animals in neuroscience and behavioural research.National Research Council. Academic Press: Washington, DC. 12.

21. Nwonu, C.N. (2011): Neuropharmacological effects of the methanolic leaf extract of Alchornea laxiflora Benth. (Euphorbiaceae) in mice. M.Sc. Thesis, Obafemi Awolowo University, Ile-Ife, Nigeria.

22. Ogundipe, O.O., Moody, J.O., Houghton, P.J. and Odelola, H.A. (2001): Bioactive chemical constituents from Alchornea laxiflora (Benth.) Pax and Hoffman. Journal of Ethnopharmacology 74 (3): $275-280$.

23. Ramesh, R. (2010): Analgesic effects of the aqueous extracts of plant Ipomea pes- tigridis studied in albino mice. Global Journal of Pharmacology 4(1): $31-35$.

24. Rujjanawate, C., Kanjanapothi, D. and Panthong, A. (2003): Pharmacological effect and toxicity of alkaloids from Gelsemium elegans Benth. Journal of Ethnopharmacology $\quad$ 89: 91 - 95.

25. Steel, R. G. D. and Torrie, J. H. (1960): Principles and Procedures of Statistics, McGraw-Hills Publishing Company Inc., London, Pp. $13-26$.

26. Wafai, Z.A. and Mehta, V.L. (1986): Some neuropharmacological actions of 3-methyl-5-phenyl-(4-methyl)-s. Indian Journal of Pharmacology 18: $89-94$. 